\title{
INVESTIGATION OF NANO-MECHANICAL AND- TRIBOLOGICAL PROPERTIES OF HYDROGENATED DIAMOND LIKE CARBON (DLC) COATINGS
}

\author{
Y.-R. Jeng \\ Department of Mechanical Engineering \\ Advanced Institute of Manufacturing with High-Tech Innovations (AIM-HI) \\ National Chung Cheng University \\ Chia-Yi, Taiwan \\ S. Islam* \\ Department of Mechanical Engineering \\ Faculty of Engineering \& Science \\ Curtin University \\ Sarawak, Malaysia \\ K-T. Wu \\ Department of Mechanical Engineering \\ National Chung Cheng University \\ Chia-Yi, Taiwan
}

\section{A. Erdemir O. Eryilmaz}

Energy Technology Division

Argonne National Laboratory

Argonne, USA

\begin{abstract}
Hydrogenated diamond like Carbon (H-DLC) is a promising lubricious coating that attracted a great deal of interest in recent years mainly because of its outstanding tribological properties. In this study, the nano-mechanical and -tribological properties of a range of H-DLC films were investigated. Specifically, four kinds of H-DLC coatings were produced on Si substrates in pure acetylene, pure methane, $25 \%$ methane $+75 \%$ hydrogen, $50 \%$ methane $+50 \%$ hydrogen discharge plasmas using a plasma enhanced chemical vapour deposition (PECVD) system. Nano indentation was performed to measure the mechanical properties such as hardness and young's modulus and nanoscartching was performed to investigate the frictional behavior and wear mechanism of the H-DLC samples in open air. Moreover, Vickers indentation method was utilized to assess the fracture toughness of the samples. The results revealed that there is a strong correlation between the mechanical properties (hardness, young's modulus, fracture toughness) and the friction coefficient of DLC coatings and the source gas chemistry. Lower hydrogen to carbon ratio in source gas leads to higher hardness, young's modulus, fracture toughness and lower friction coefficient. Furthermore, lower wear volume of the coated materials was observed when the friction coefficient was lower. It was also confirmed that lower hydrogen content of the DLC coating leads to higher wear resistance under nanoscratch conditions.
\end{abstract}

Keywords: Hydrogenated DLC coating, Hardness, Fracture toughness, Wear.

* Corresponding author (sumaiya.islam18@gmail.com) 


\section{INTRODUCTION}

Many unique properties of diamond-like carbon (DLC) coatings together with the possibility of adjusting their properties by choosing the right combination of deposition parameters and or conditions, have made this class of coating very attractive for a wide range of industrial applications [1-7]. Among others, their super-low friction and wear coefficients together with high resistance to corrosion and oxidation made them very desirable not only for engine and magnetic hard disk applications but also for high precision ball bearing applications and aerospace mechanisms. It is therefore very natural that a lot of research efforts have been directed toward the characterization of the tribological properties of DLC coatings at micro and macro scales [8-11] using a variety of micro-tribology and pin-on-disk type instruments [12]. However, an in depth understanding of the relationship between the physico-chemical characteristics of DLCs and their tribo mechanical behavior has been relatively unexplored, especially at nano scale.

A variety of methods including d.c- and r.f physical vapour deposition (PVD) and chemical vapour deposition (CVD) are used to deposit DLC coatings on metallic substrates. Depending on the carbon source used, they can be made either hydrogenated or nearly hydrogen-free exhibiting a wide range of structure, property and performance, such as low friction, high wear resistance, chemical inertness, relatively high optical band gap and high electrical resistivity [3, 10, 13-15]. Among many other coating types, DLC films represent a unique example whose tribological behavior strongly depends both on the nature of the coating (controlled by the deposition procedure) and the test parameters, including contact pressure, speed, temperature and chemical nature of the test environment $[8,16]$. In particular, depending on the deposition method, the hydrogen concentration in DLC may range from less than a few to $10-50$ atomic \% [4]. Hydrogen in DLC is important because it impacts the physical, chemical, mechanical and tribological properties. For example, in highly hydrogenated DLCs, it passivates the dangling bonds in the random amorphous network structure and thus provide a wide optical band gap and a high electrical resistivity, removing mid gap defect states, stabilizing the random network and preventing its collapse into a graphitic phase [4, 10]. Further improvements in the tribological behavior and expanding the use of DLC coatings for tribological protection in new applications require a better understanding of the friction and wear mechanisms of these coatings at nano/micro scales in relation to the coatings mechanical properties.

Intensive research has been done on the measurement of hardness and elastic modulus of such hydrogenated DLC coatings at micro and macro scale [5, 17-20], however, very little is understood on their fracture toughness and nano-scratch behavior. The trend of mineralization drives the increasing demand of applying MEMS/NEMS systems. High surface to volume ratio in such devices renders nano-scale tribology playing a pivotal role in their performance. Moreover, recent studies on nanotribology elucidate that nano-scale mechanism underpins the interfacial behavior of the system [3]. Therefore, the primary objective of this paper is to evaluate the mechanical (hardness, young's modulus and toughness) and tribological (wear and friction) properties at nano scale of different kinds of H-DLC coatings that were produced by plasma enhanced chemical vapour deposition (PECVD) method, by using four distinct gas discharge plasmas where hydrogen to carbon ratios were varied. Furthermore, it was tried to establish a correlation between these mechanical and tribological properties of $\mathrm{H}$-DLC coatings with different Hydrogen to carbon ratio.

\section{EXPERIMENTAL DETAILS}

In this study, oxford plasma lab 100 inductively coupled PECVD was utilized to deposit the H-DLC coatings on silicon substrates at room temperature. The procedure for forming DLC coatings on $\mathrm{Si}$ substrates by PECVD involved sputter-cleaning of the substrates in an Ar plasma for 30 min by applying a $1200-1700 \mathrm{~V}$ bias. Then the Si substrates were coated with 50-70 nm thick silicon bond layer using silane $\left(\mathrm{SiH}_{4}\right)$ gas by switching to a sputtering mode. Finally, carbon bearing source gases were bled into the chamber and commencing the deposition of DLCs on substrates. Typical gas pressure and r.f during coating deposition were maintained 13 mTorr and $1600 \mathrm{~V}$ respectively. Further details of this deposition process and hydrogenated DLC coatings can be found elsewhere [3, 21-26].

Table1 shows the precursor source gases and the designation of the tested samples, as well as the hydrogen to carbon ratio in source gas. Hydrogen Forward Scattering (HFS) has been used to determine the amount of hydrogen in the coatings $[6,21,22]$. A micro laser Raman spectrometer (Renishaw) was used with an Ar ion laser $(514.5 \mathrm{~nm})$ to analyze the structural chemistry of H-DLC coatings derived from different source gases.

Table 1 Samples designation, Precursor gases, $\mathrm{H} / \mathrm{C}$ ratio in source gas and Derived parameters

\begin{tabular}{|c|c|c|c|c|}
\hline $\begin{array}{c}\text { Sample } \\
\text { designation }\end{array}$ & NFC6 & NFC2 & NFC7 & NFC10 \\
\hline Precursor gases & $\begin{array}{c}25 \% \mathrm{CH}_{4} \\
+75 \% \mathrm{H}_{2}\end{array}$ & $\begin{array}{c}50 \% \mathrm{CH}_{4} \\
+50 \% \mathrm{H}_{2}\end{array}$ & $100 \% \mathrm{CH}_{4}$ & $100 \% \mathrm{C}_{2} \mathrm{H}_{2}$ \\
\hline $\begin{array}{c}\mathrm{H} / \mathrm{C} \text { ratio in } \\
\text { source gas }\end{array}$ & 10 & 6 & 4 & 1 \\
\hline $\begin{array}{c}\text { Derived } \\
\text { parameters } \\
\left(\begin{array}{c}\text { (Coating com- } \\
\text { position })\end{array}\right.\end{array}$ & $\begin{array}{c}39 \% \mathrm{H} \\
+61 \% \mathrm{C}\end{array}$ & $\begin{array}{c}39 \% \mathrm{H} \\
+61 \% \mathrm{C}\end{array}$ & $\begin{array}{c}45 \% \mathrm{H} \\
+55 \% \mathrm{C}\end{array}$ & $\begin{array}{c}30 \% \mathrm{H} \\
+70 \% \mathrm{C}\end{array}$ \\
\hline
\end{tabular}

To measure the mechanical properties of the H-DLC coatings, nanoindentation method was performed with a Berkovich tip having a tip radius of $100 \mathrm{~nm}$. For indentation purposes, $1000 \mu \mathrm{N}$ normal load was used. All experiments were carried out under room temperature and normal atmospheric conditions with a temperature range of $20-24^{\circ} \mathrm{C}$ and relative humidity range of $(45-50) \%$.

Vickers indentation method can provide some indication of the fracture toughness of coatings as described in 
detail in Ref. [27]. Accordingly, to assess the fracture toughness of the H-DLC coatings, Vickers indenter was used to explore the fracture toughness of the DLC coating by creating a crack on the coating surface using a $200 \mathrm{gf}$ load and after that, using a Scanning Electron Microscope (SEM) to measure the crack length. Measured values were then used to calculate the fracture toughness of the DLC coatings according to the method described in Ref. 27.

To investigate the tribological properties, such as friction and wear of the coatings, nanoscratching method was conducted using a Hysitron nanoindenter (Hysitron Inc.) with a conical tip $(500 \mathrm{~nm})$. The scratch length and the velocity were kept constant at $10 \mu \mathrm{m}$ and $333 \mathrm{~nm} / \mathrm{s}$ respectively. The topographic scanning method was employed to analyze the depth of the scratched surface and the area of the topographic measurement was $10 \times$ $10 \mu \mathrm{m}^{2}$. In a scanning mode, a $20 \mu \mathrm{m} / \mathrm{s}$ tip velocity and $1 \mathrm{~Hz}$ scan rate were used. Subsequently, Atomic Force Microscope (AFM) was used to scan the nano-scratched regions to further investigate the wear characteristics of these hydrogenated DLC coatings.

\section{RESULTS \& DISCUSSIONS}

The Raman spectra of the coatings derived from various source gases are shown in Fig. 1. Essentially, these spectra revealed broad peaks centered at or near $\sim 1560$ $\mathrm{cm}^{-1}$ and shouldered peaks at $\sim 1350 \mathrm{~cm}^{-1}[9,11]$. The shouldered peaks were somewhat less pronounced on coatings produced in acetylene plasma where $\mathrm{H} / \mathrm{C}$ ratio was 1. Overall, the films displayed Raman features typical of DLC films and were consistent with the Raman spectra presented elsewhere [28-30].

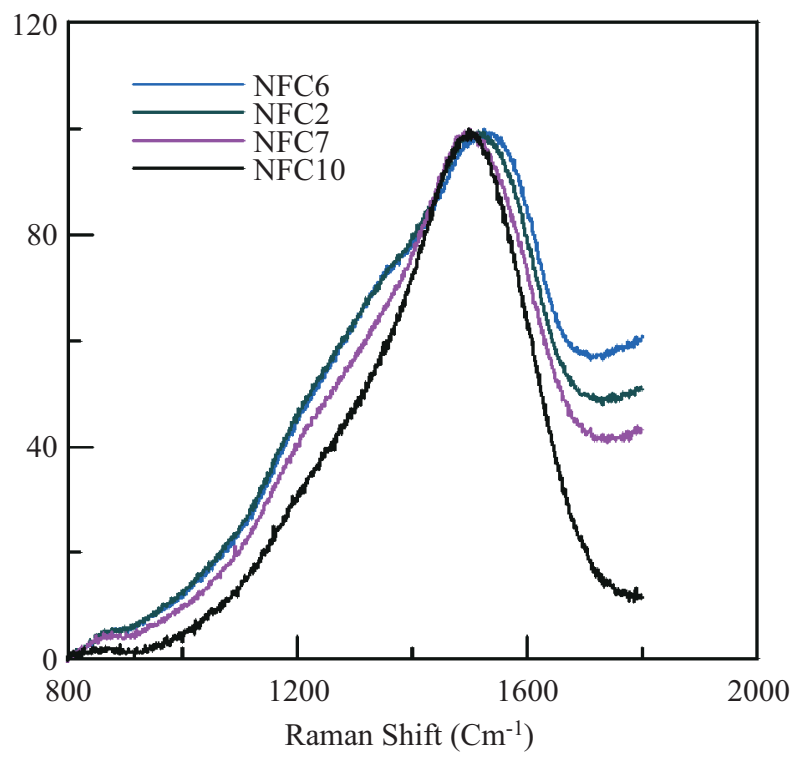

Fig. 1 Laser Raman spectra of NFC6, NFC2, NFC7 and NFC10 DLC samples.

Figure 2 shows the load displacement curve for each sample when nano indentations were performed using $1000 \mu \mathrm{N}$ normal load. Oliver-Pharr method was utilized to determine the hardness and elastic modulus of the samples using one complete cycle of loading and unloading [31]. Regarding the hardness and young's modulus of the hydrogenated DLC coatings it was found that the maximum penetration depth during indentation were approximately $40-80 \mathrm{~nm}$ which is 30 times less than the coating thickness. Therefore, the hardness values reported were mostly for the DLC coatings and there was not any influence from the substrate Si. Thus these hardness values can be considered as the absolute hardness of the H-DLC coatings. The values of these hardness are different from the previous literature where micro hardness were measured for the film with the substrate effect [5].

The obtained hardness and young's modulus values of different H-DLC coatings are plotted in Fig. 3. It shows that the lowest and highest values of hardness and young's modulus were observed when nanoindentation was performed on the samples NFC6 and NFC10 respectively. It is important to note that NFC10 was produced in a plasma which had the smallest hydrogen to carbon ratio, i.e., 1; while NFC6 was produced in a plasma with hydrogen to carbon ratio of 10 . It can be concluded from Fig. 3 that the NFC10 coating, which was grown in a plasma with the smallest hydrogen to carbon ratio, is much harder than the other hydrogenated coatings [31]. This result is expected to a certain extent since, as the hydrogen to carbon ratio in source gas decreases the degree of $\mathrm{sp}^{3}$ bonding shifts from more $\mathrm{C}-\mathrm{H}$ to more $\mathrm{C}-\mathrm{C}$ bonds leading, consequently, to a stronger network of the H-DLC coating, thus to a coating of higher hardness [5, 32]. Therefore, highest hardness and young's modulus were observed when nanoindentation was performed on the DLC coatings where hydrogen to carbon ratio in source gas was 1 .

The fracture toughness of these H-DLC coatings were evaluated by performing Vickers pyramid indentations at loads sufficient for significant deformation of the H-DLC coatings to induce cohesive radial cracks. Amorphous $\mathrm{H}$-DLC coatings tested in this study easily developed the cohesive radial cracks under Vickers indentation with a 200 gf load (shown in Fig. 4) indicating low cohesion and adhesion strength. The crack lengths of the different samples were measured using scanning electron microscope (SEM) and large crack lengths were found when indentation was performed on NFC6 sample as shown in Fig. 4. According to previous literature [33, 34], it was known that the progression of fracture process can be explained in two stages: first, ring-like throughthickness cracks form around the indenter by high stresses in the contact area; second, delamination and buckling occur around contact area at the coating/substrate interface by high lateral pressure and shown in Fig. 4.

Elastic-plastic deformation was found when these $\mathrm{H}$ DLC coatings were subjected to Vickers indentation and the strain energy released in the radial cracking and these crack lengths were measured by SEM and then fracture toughness were calculated based on Eq. 1. The residual stress $\left(\sigma_{R}\right)$ values for different coatings are measured and given in Table 2. 

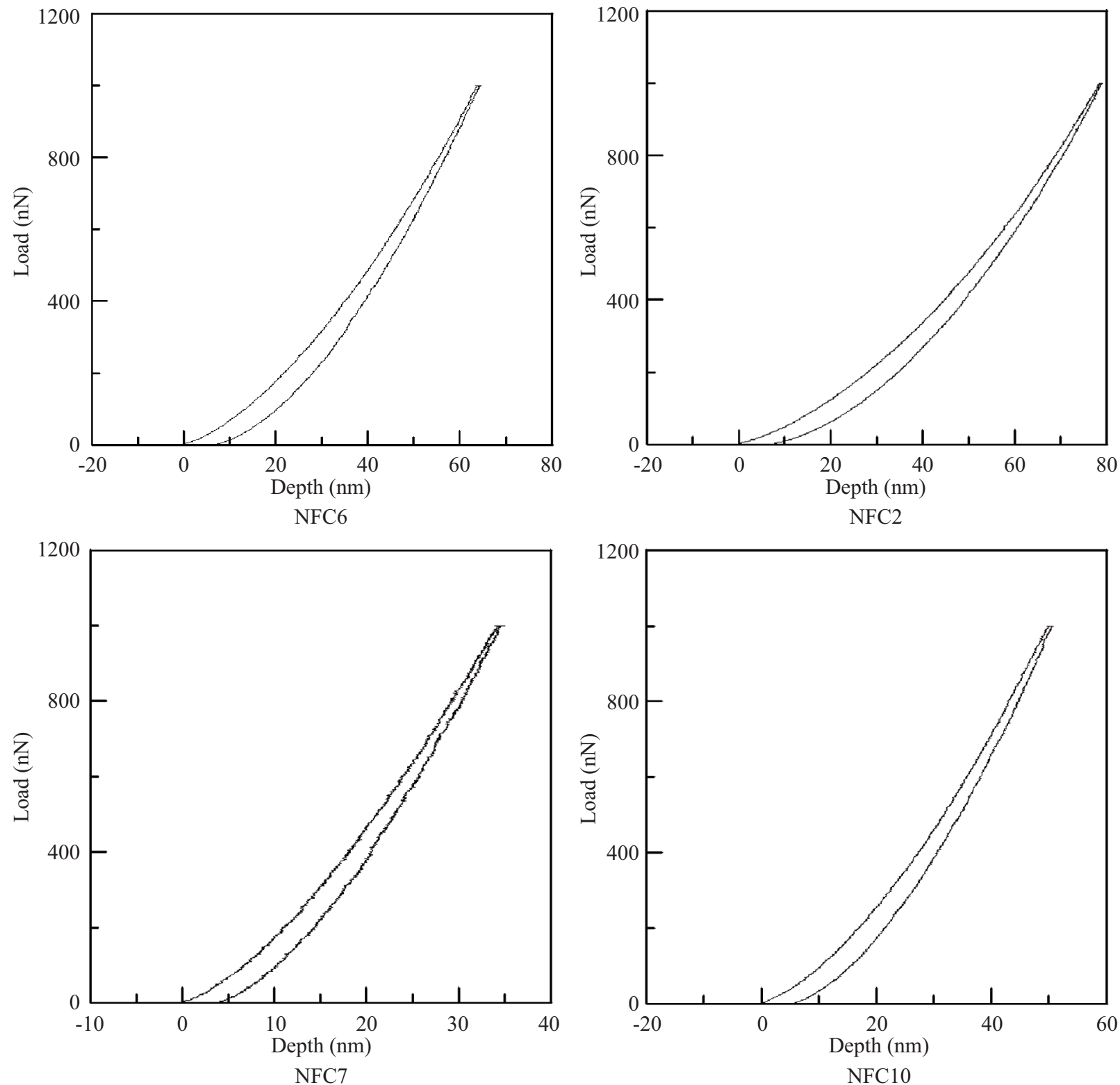

Fig. 2 The typical load displacement curve for NFC6, NFC2, NFC7 and NFC10 samples.

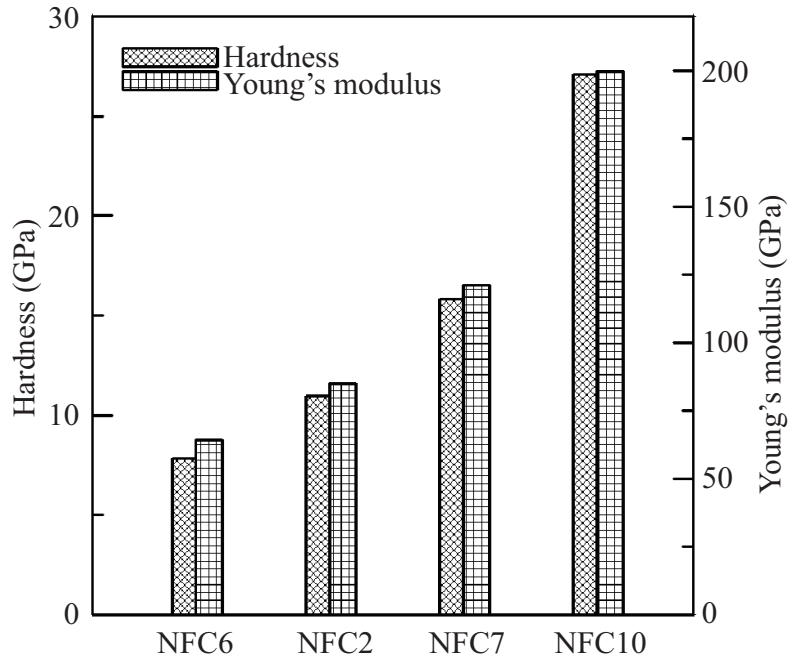

Fig. 3 Hardness and Young's modulus of different H-DLC coatings.

$$
\begin{gathered}
K=\lambda^{\prime} V^{*}\left(\frac{E_{f}}{H_{f}}\right)^{1 / 3} \frac{1}{t_{f}} \frac{P}{c^{1 / 2}}+\psi \sigma_{R} t_{f}^{1 / 2} \ldots \ldots . . \\
V^{*}=\left\{\begin{array}{l}
1, h_{p} \leq t_{f} \\
1-\frac{\left(h_{p}-t_{f}\right)^{3}}{h_{p}^{3}}, h_{p}>t_{f}
\end{array}\right.
\end{gathered}
$$

where $E_{f}$ is elastic modulus of the coating, $H_{f}$ is hardness of the coating, $\sigma_{R}$ is residual stress, $P$ is the applied load, $c$ is the crack length, $\eta$ is a tip shape constant for ideal tip geometries, $V^{*}$ is exclude any plasticity in the substrate, $\lambda$ is the Poisson's ratio and the specific tip geometry ( 0.013 for Vickers geometry), $\lambda^{\prime}$ is $\lambda / \eta$ ( $\eta=1.299$----cube corner), $\Psi^{\prime}$ is equal to 0.916 for a channel crack, $t_{f}$ is the coating thickness and $h_{p}$ is the residual plastic displacement. 


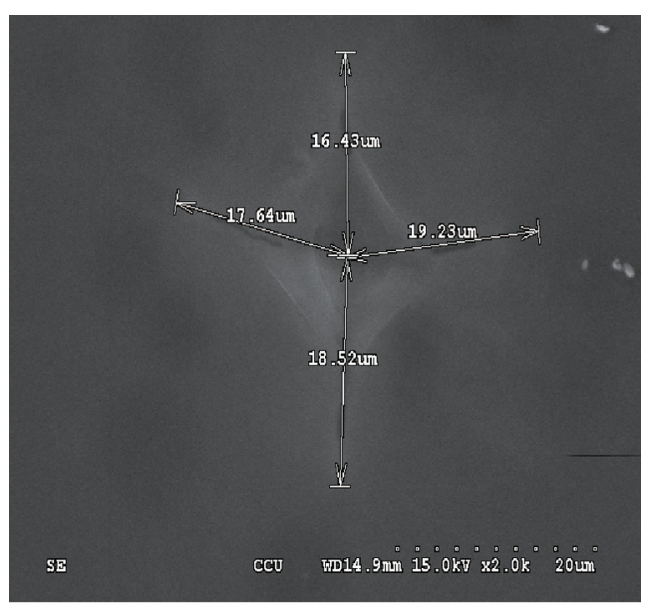

NFC6

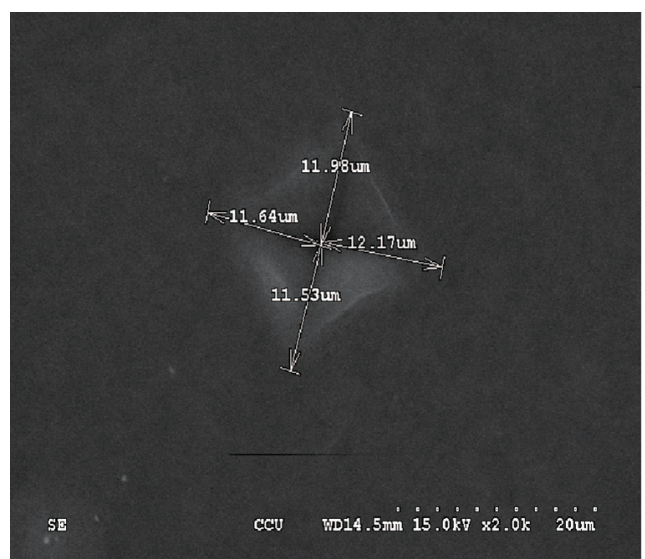

NFC7

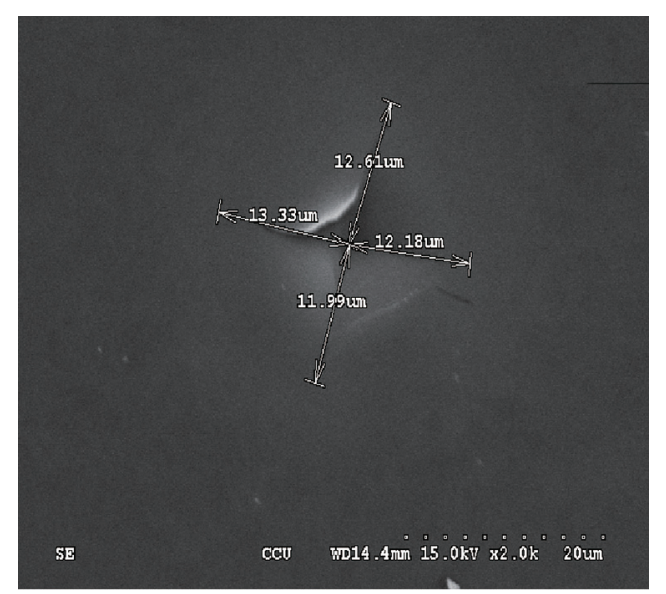

NFC2

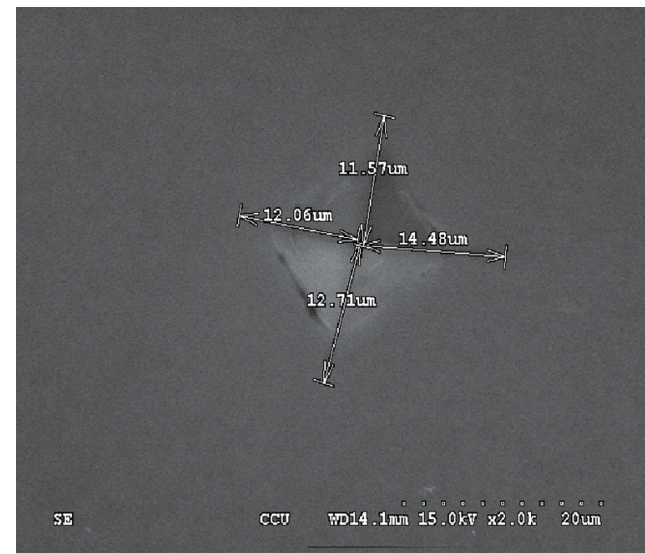

NFC10

Fig. 4 SEM images of Vickers indentation sites on the H-DLC coatings.

Table 2 Residual stresses for different samples

\begin{tabular}{|c|c|c|c|c|}
\hline $\begin{array}{c}\text { Sample } \\
\text { designation }\end{array}$ & NFC6 & NFC2 & NFC7 & NFC10 \\
\hline $\begin{array}{c}\text { Residual stress, } \\
\sigma_{\mathrm{R}}(\mathrm{GPa})\end{array}$ & 0.22 & 0.83 & 0.77 & 1.77 \\
\hline
\end{tabular}

Figure 5 shows that the toughness of the H-DLC coatings increased when hydrogen to carbon ratio in source gas decrease from 10 to 1 . Furthermore, the lowest toughness value was found when Vickers indentation was performed on NFC6 sample. These results reveal that hydrogen has a great influence on these $\mathrm{H}$ -DLC coatings to change their toughness property. The decrease of Hydrogen means the increase of $\mathrm{sp}^{2} / \mathrm{sp}^{3}$ ratio and in that case $\mathrm{C}-\mathrm{C}$ bonding was more dominant on the coating and this kind of bonding may have resulted in the higher toughness of the coating.

It is known that hydrogen plays an important role in the frictional behavior of DLC coatings (especially in inert or vacuum environments [6]). The friction tests were carried out under elastic-plastic contact conditions in open air to further confirm if hydrogen has any effect on friction of DLC coatings tested in this study at nano-scale. Figure 6 shows that the variations of the friction coefficient as a function of time for different DLC coatings. Although some scatter and fluctuations

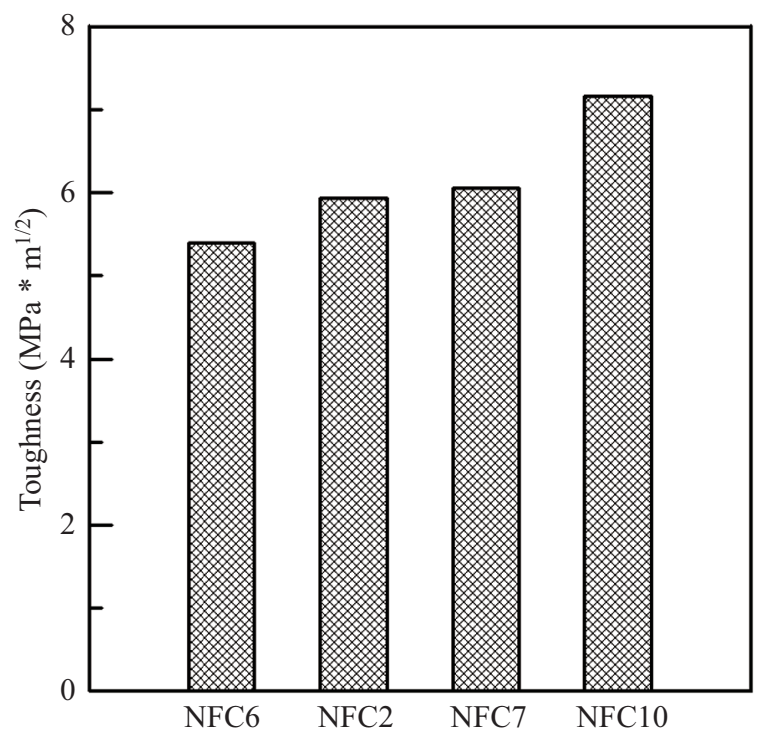

Fig. 5 Fracture toughness of different H-DLC coatings.

of the friction coefficient occurred during the scratching operation on H-DLC coating, it can be clearly observed that, at the initial stage (during 12-15 second) friction coefficient initially increased and then these values dropped and showed a tendency to get even lower with the change in time. 


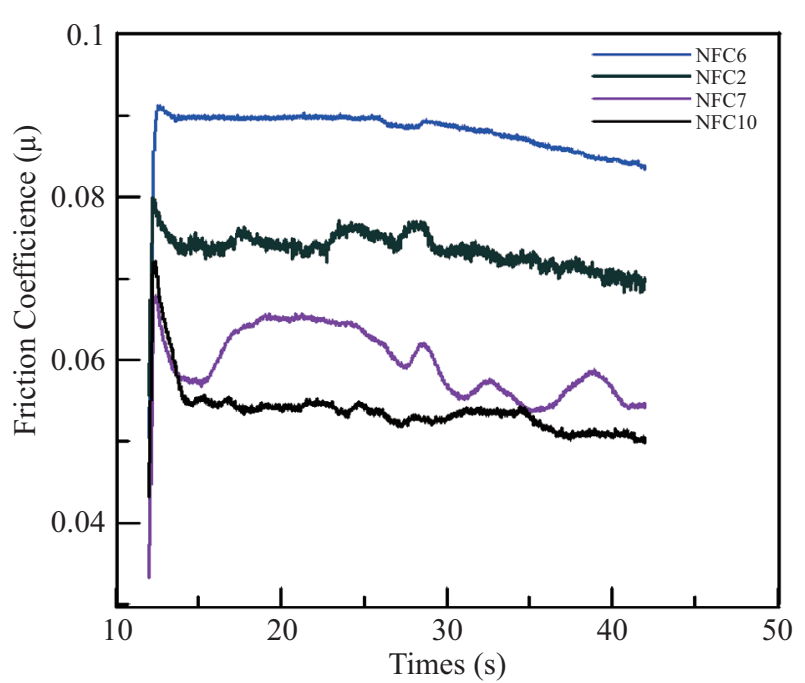

Fig. 6 Variation in the friction Co-efficient of different H-DLC coatings.

As is clear from Fig. 6, harder DLC samples with lower hydrogen to carbon ratios have a tendency to exhibit lower friction coefficients in the open air sliding conditions. Therefore, it was shown that NFC6 sample afforded much higher friction coefficient with its lower hardness which may lead to some wear damage, thus making the sliding surface rougher which can lead to higher friction. This is because much softer nature of the surface NFC6 coating, the contact area between the film and the tip was much larger than the other three films tested. On such a larger contact area, the extent of adhesion may be greater and this may also lead to higher frictional forces and hence friction.

It was found that friction at sliding diamond and DLC interfaces may result from a combination of short and long-range chemical and or physical interactions (i.e. covalent, van der Waals forces, electrostatic attractions, capillary forces, etc.)[35]. In humid test environments, capillary forces can also play a significant role in friction (especially at nano-scales), Under extreme pressure conditions, strong covalent and relatively wеak л-л* interactions as well as van der Waals forces may also be present and can dominate the frictional behavior of H-DLC coatings $[10,14]$.

Figure 7 shows the 3D AFM images of the scratched profile with wear depth value of the H- DLC coatings. Largest groove depth $12.24 \mathrm{~nm}$ was observed when scratching was performed on NFC6 sample (which was the softest of all DLCs tested). Depth of the scratched profile reveals the wear behavior of the coatings. The wear volumes of the samples were also calculated and presented in Fig. 8. Wear volume is the indication of the wear resistant of the materials [36-39].Larger wear volume reveals the less wear resistant of the coating and it was found that, wear volume was larger of the sample NFC6 than that of the other samples.

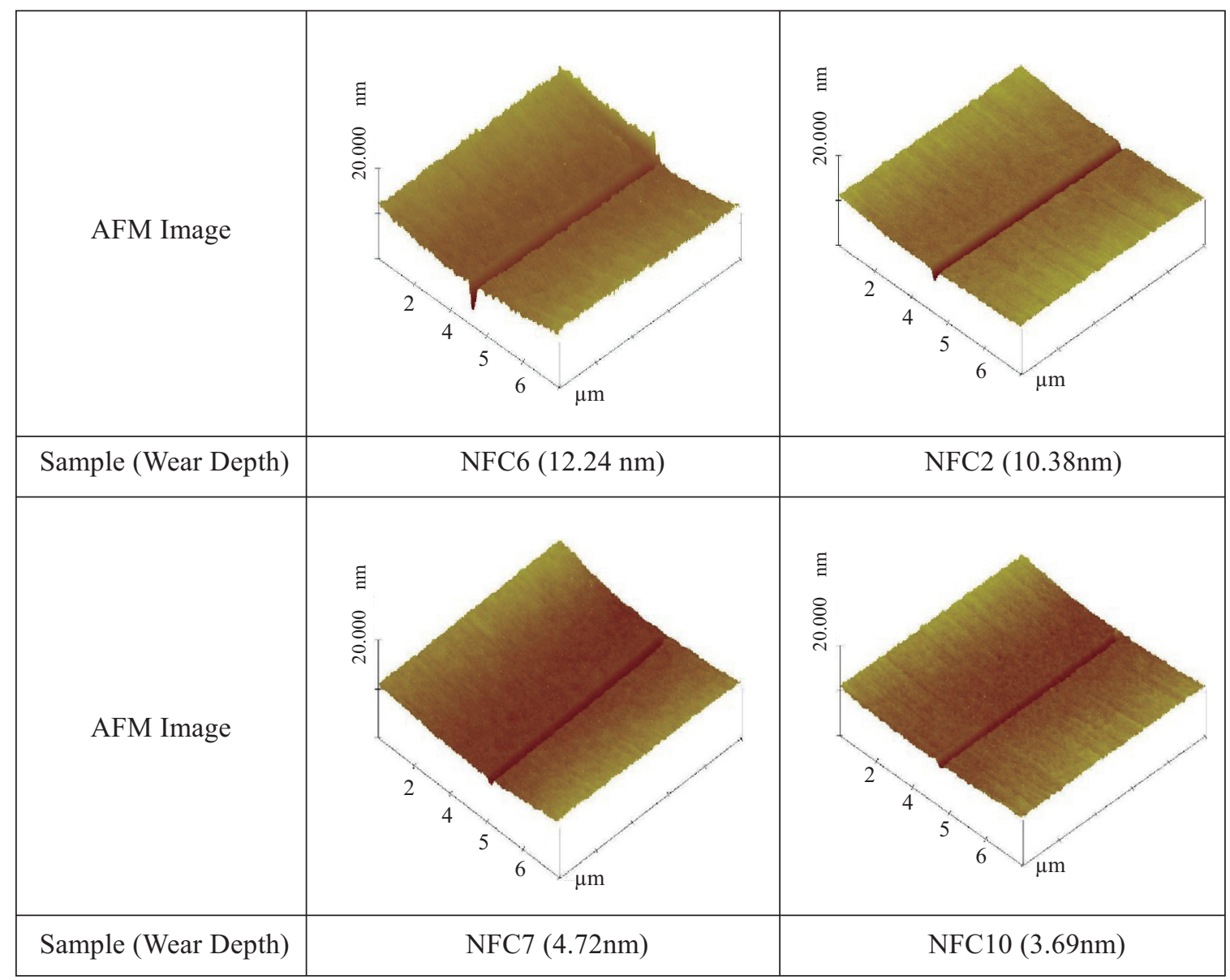

Fig. 7 3D view of the scratched profile of different H-DLC coatings. 


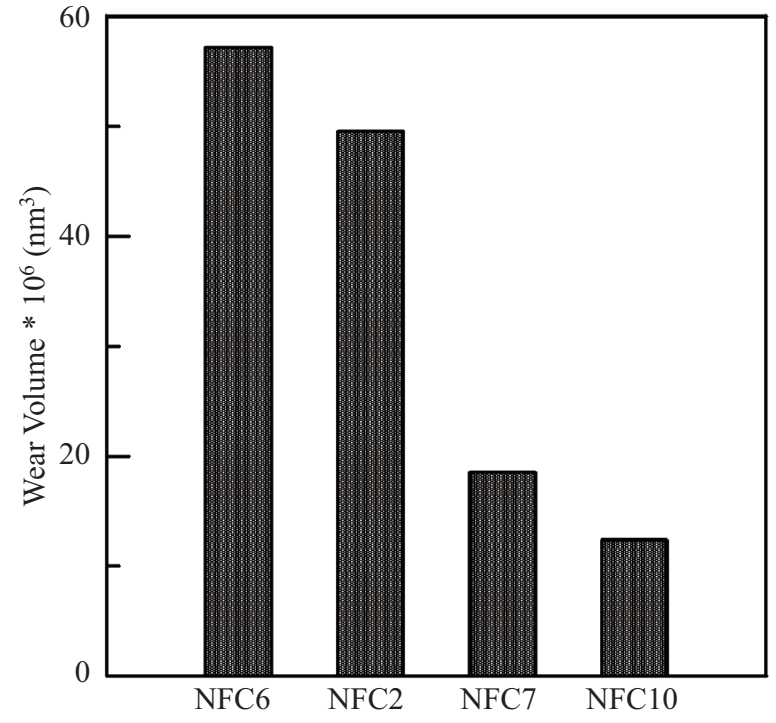

Fig. 8 Wear volume of different H-DLC coatings.

The wear mechanism in coatings appears to be purely abrasive for all the tested materials with $3000 \mu \mathrm{N}$ normal force, the abrasive wear mechanism were dominated for all H-DLC coatings. When the wear volume is larger it means that it caused highest friction due to the loosen nano debris particles trapped between the contacting surfaces. Therefore, highest wear volume and friction coefficient were found at NFC6, and it seems it is related to the balance between the hardness of the film and the extent of the $\mathrm{sp}^{2} / \mathrm{sp}^{3}$ ratio. In this way, NFC10 coating is the hardest (more $\mathrm{C}-\mathrm{C}$ bonds) but according to Angus and Janson [40] should have a highest $\mathrm{sp}^{2} / \mathrm{sp}^{3}$ ratio. The $\mathrm{sp}^{2}$ bonds will tend to favour smearing of the surface layers, promoting delamination of the film rather than abrasion, therefore less wear volume were observed. Conversely, NFC6 is softer (more hydrogen in the network) but has a higher degree of $\mathrm{sp}^{3}$ bonds. The $\mathrm{sp}^{3}$ bonds will tend to impair smearing of layers and occurrence of microplastic deformation. Therefore, once the wear threshold is overcome, the active wear mechanisms in these samples tend to be due to abrasion by the scratching as were observed [5].

\section{CONCLUSIONS}

This study investigated the mechanical and tribological behavior of diamond-like carbon coatings where hydrogen to carbon ratio in source gas was varied. The following conclusions can be drawn from this present study.

1. When hydrogen to carbon ratio in source gas of the DLC coating decreases from 10 to 1 , the degree of $\mathrm{sp}^{3}$ bonding shifts from more $\mathrm{C}-\mathrm{H}$ to more $\mathrm{C}-\mathrm{C}$ bonds resulting into a stronger network of the coating. Therefore, the mechanical properties such as fracture toughness, hardness and elastic modulus of the coatings increases. Likewise, the friction coefficient and wear volume decrease with the decrease of the hydrogen to carbon ratio in source gas.
2. High fracture toughness, hardness and young's modulus are responsible for improved friction and wear behavior of the hydrogenated DLC coatings in open air.

3. Good mechanical and tribological properties can be obtained when hydrogen to carbon ratio in source gas is maintained at 1 .

\section{REFERENCES}

1. Gangopadhyay, A., et al., "Friction, wear, and surface film formation characteristics of diamond-like carbon thin coating in valve train application," Tribology Transactions, 54, pp. 104-114 (2011).

2. Huang, S.J., Jeng, Y.R. and Liu, K.F., "Sliding wear characteristics of the diamond-like carbon films on alloy substrates," Wear, 263, pp. 1266-1273 (2007).

3. Jeng, Y.R., et al., "Effect of feed gas composition effects on the nanotribological properties of diamond-like carbon films," Thin Solid Films, 529, pp. 301-305 (2013).

4. Grill, A., "Diamond-like carbon: state of the art," Diamond and Related Materials, 8, pp. 428-434 (1999).

5. Colaco, R., Serro, A.P., Eryilmaz, O. L. and Erdemir, A., "Micro-to-nano triboactivity of hydrogenated DLC films," Journal of Physics D: Applied Physics, 42, pp. 1-8 (2009).

6. Erdemir, A., "The role of hydrogen in tribological properties of diamond-like carbon films," Surface and Coatings Technology, 146, pp. 292-297 (2001).

7. Gonzalez, R., Battez, H., Viesca, J.L., Garrodo, A.H. and Gozalez, A.F., "Lubrication of DLC coatings with two tris (pentafluoroethyl) trifluorophosphate anion-based ionic liquids," Tribology Transactions, 56, pp. 887-895 (2013).

8. Erdemir, A., Bindal, C., Pagan, J. and Wilbur, P., "Characterization of transfer layers on steel surfaces sliding against diamond-like hydrocarbon films in dry nitrogen," Surface and Coatings Technology, 76-77, pp. 559-563 (1995).

9. Erdemir, A., Eryilmaz, O. L., Nilufer, B. and Fenske, G.R., "Effect of source gas chemistry on tribological performance of diamond-like carbon films," Diamond and Related Materials, 9, pp. 632-637 (2000).

10. Erdemir, A. Nichols, F. A., Pan, X. Z., Wei, R. and Wilbur, P., "Friction and wear performance of ionbeam-deposited diamond-like carbon films on steel substrates," Diamond and Related Materials, 3, pp. 119-125 (1993).

11. Erdemir, A., Nilufer, I.B., Eryilmaz, O.L., Beschliesser, M. and Fenske, G.R., "Friction and wear performance of diamond-like carbon films grown in various source gas plasmas," Surface and Coatings Technology, 120, pp. 589-593(1999).

12. Bhushan, B., "Chemical, mechanical and tribological characterization of ultra-thin and hard amorphous carbon coatings as thin as $3.5 \mathrm{~nm}$ : recent developments," Diamond and Related Materials, 8, pp. 1985-2015 (1999). 
13. Mistry, K. K., et al., "Synthesis and tribology of micro-carbon sphere additives for enhanced lubrication," Tribology Transactions, 58, pp. 474-480 (2015).

14. Erdemir, A., et al., "Friction and wear properties of smooth diamond films grown in fullerene + argon plasmas," Diamond and Related Materials, 5, pp. 923-931 (1996).

15. Meletis, E., Erdemir, A. and Fenske, G.R., "Tribological characteristics of DLC films and duplex plasma nitriding/DLC coating treatments," Surface and Coatings Technology, 73, pp. 39-45 (1995).

16. Liu, Y., Erdemir, A. and Meletis, E.I., "Influence of environmental parameters on the frictional behavior of DLC coatings," Surface and Coatings Technology, 94-95, pp. 463-468 (1997).

17. White, R. L., Doerner, M. F. and Walker, G. W., "Mechanical properties of carbon films for thin film disks," MRS Proceedings, 188, pp. 213-218 (1990).

18. Bhushan, B. and Doerner, M.F., "Role of mechanical properties and surface texture in the real area of contact of magnetic rigid disks," ASME Journal of Tribology, 3, pp. $452-458$ (1989).

19. Bhushan, A.B., Kellock, J., Cho, N-H. and Ager, J. W., "Characterization of chemical bonding and physical characteristics of diamond-like amorphous carbon and diamond films," Journal of Materials Research, 7, pp. 404-410 (1992).

20. Gupta, B.K. and Bhushan, B., "Mechanical and tribological properties of hard carbon coatings for magnetic recording heads," Wear, 190, pp. 110-122 (1995).

21. Erdemir, A., Eryilmaz, O.L. and Fenske, G., "Synthesis of diamond like carbon films with super low friction and wear properties," Journal of Vacuum Science and Technology A, 18, pp. 1987-1992 (2000).

22. Johnson, J. A., et al., "Insights into near-frictionless carbon films," Journal of Applied Physics, 95, pp. 7765-7771 (2004).

23. Kim, H.I., Lince, J.R., Eryilmaz, O.L. and Erdemir. A., "Environmental effects on the friction of hydrogenated DLC films," Tribology Letters, 21, pp. 5156 (2006).

24. Eryilmaz, O.L. and Erdemir, A., "Tof-sims and xps characterization of diamond-like carbon films after tests in inert and oxidizing environments," Wear, 265, pp. 244-254 (2008).

25. Horsfall. R.H., "Commercial applications using nonhydrogenated carbon films for industrial uses such as cutting tools and wear components," Proceedings of the 41st Annual Technical Conference, Society of Vacuum Coaters, Boston, MA, USA (1998).

26. Sullivan, J.P., Friedmann, T.A. and Hjort. K., "Diamond and amorphous carbon mems," MRS Bulletin, 26, pp. 309-311 (2001).

27. Laugier, M. T., "Palmqvist indentation toughness in WC-Co composites," Journal of Materials Science
Letters, 6, pp. 897-900 (1987).

28. Tsai, H. and Bogy, D. B., "Characterization of diamond like carbon films and their application as overcoats on thin film media for magnetic recording," Journal of Vacuum Science \& Technology A: Vacuum, Surfaces, and Films, 5, pp. 3287-3312 (1987).

29. Knight, D.S. and White, W.B., "Characterization of diamond films by raman spectroscopy," Journal of Materials Research, 4, pp. 385-393 (1989).

30. Robertson, J., "Amorphous carbon," Advances in Physics, 35, pp. 317-321 (1986).

31. Donnet, C. and Erdemir, A., Tribology of Diamond Like Carbon Films, Springer, Berlin (2008).

32. Oliver, W.C. and Phar, M. G., "An improved technique for determining hardness and elastic modulus using load and displacement sensing indentation experiments," Journal of Material Research, pp. 15641583 (1992).

33. Li, X. and Bhushan, B., "Measurement of fracture toughness of ultra-thin amorphous carbon films," Thin Solid Films, 315, pp. 214-221(1998).

34. Li, X., Diao, D. and Bhushan, B., "Fracture mechanisms of thin amorphous carbon films in nanoindentation," Acta Materialia, 45, pp. 4453-4461 (1997).

35. Donnet, C., et al., "The respective role of oxygen and water vapor on the tribology of hydrogenated diamond-like carbon coatings," Tribology Letters, 4, pp. 259-265 (1998).

36. Islam, S., Ibrahim, R. and Khandoker, N., "The mechanics of single crystal cu machining at nanoscale," Procedia Engineering, 10, pp. 2369-2374 (2011).

37. Islam, S. and Ibrahim, R., "Investigation of deformation behaviour and abrasive wear mechanism in nanomachining," International Journal of Surface Science and Engineering, 5, pp. 38-50 (2011).

38. Islam, S. and Ibrahim, R., "Mechanism of abrasive wear in nanomachining," Tribology Letters, 42, pp. 275-284 (2011).

39. Islam, S., Ibrahim, R.N. and Das, R., "Study of abrasive wear mechanism through nano machining," Key Engineering Materials, 462, pp. 931-936 (2011).

40. Angus, J. C. and Jansen. F., "Dense diamond like hydrocarbons as random covalent networks," Journal of Vacuum Science \& Technology, A: Vacuum, Surfaces, and Films, 6, pp. 1778-1784 (1998).

(Manuscript received May 31, 2016, accepted for publication September 20, 2016.) 